\title{
Homework in Elementary School
}

\author{
Ratna Hidayah, Moh Salimi, Suhartono, Tri Saptuti Susiani, Ngatman
}

Universitas Sebelas Maret

ratnahidayah@staff.uns.ac.id

\section{Article History}

accepted 05/11/2020

\begin{abstract}
Education is invesment for the future. The phrase discribed how attractiveness the future with prosperity, a society desirable. But it could not be reached without efforts from anyone who involved in education process. School, family, and society was centered of education. In those institution education held. So, it was plausibility disscuss the cooperation of those institution. Our focus disscuss was homework as medium to cooperate between school and family. The cooperation between one institution with onether for long time means empowering the institution it self. Homework is a time honored practice that can enhance the development of skills and reinforce knowledge gained within the classroom when it used effectively and appropriately. The purposes of homework serve three main functions instructional, communicative, and political. In instructional function, homework is natural extention of the curricular programs because it is an integral component of instruction. It can also serve as a vital link between theschool and family.

Keywords: homework, elementary school
\end{abstract}

\section{Abstrak}

Pendidikan adalah investasi untuk masa depan. Ungkapan itu menggambarkan betapa menariknya masa depan dengan kemakmuran, yang diinginkan masyarakat. Tapi itu tidak bisa dicapai tanpa upaya dari siapapun yang terlibat dalam proses pendidikan. Sekolah, keluarga, dan masyarakat berpusat pada pendidikan. Di institusi itulah pendidikan diadakan. Jadi, wajar saja jika membahas kerja sama kedua lembaga tersebut. Fokus diskusi kami adalah pekerjaan rumah sebagai sarana kerjasama antara sekolah dan keluarga. Kerja sama antara satu lembaga dengan lembaga yang sudah lama ada berarti memberdayakan lembaga itu sendiri. Pekerjaan rumah adalah praktik penghargaan waktu yang dapat meningkatkan pengembangan keterampilan dan memperkuat pengetahuan yang diperoleh di dalam kelas jika digunakan secara efektif dan tepat. Tujuan pekerjaan rumah melayani tiga fungsi utama instruksional, komunikatif, dan politik. Dalam fungsi instruksional, pekerjaan rumah adalah perpanjangan alami dari program kurikuler karena merupakan komponen integral dari pengajaran. Itu juga dapat berfungsi sebagai penghubung penting antara sekolah dan keluarga.

Kata kunci: pekerjaan rumah, sekolah dasar

Social, Humanities, and Education Studies (SHEs): Conference Series https://jurnal.uns.ac.id/shes 


\section{PENDAHULUAN}

Homework atau Pekerjaan Rumah (PR) dari guru di sekolah merupakan hal yang rutin didapatkan siswa. Mengerjakan PR merupakan kewajiban bagi para siswa. Memberikan PR kepada siswa untuk dikerjakan, dirasa memiliki banyak memanfaat salah satunya meningkatkan kemampuan akademis siswa. Pemberian pekerjaan rumah yang diberikan oleh guru kepada siswa diharapkan dapat menjadikan siswa untuk lebih aktif dan mandiri dalam proses belajarnya, serta dapat meningkatkan penguasaan lebih terhadap materi yang telah disampaikan oleh guru. Pemberian pekerjaan rumah tersebut meliputi frekuensi pemberian yang teratur dalam artian intensitas atau sering tidaknya pemberian tugas rumah dan banyaknya pekerjaan rumah yang diberikan oleh guru kepada siswa serta kualitas pekerjaan rumah. Berdasarkan survey, guru memiliki anggapan bahwa pekerjaan rumah yang diberikan di sekolah akan membuat siswanya belajar dirumah. Jika tidak ada tugas yang harus dikerjakan dirumah siswa tidak akan belajar. Semakin sering dan banyak siswa mengerjakan PR akan membuat siswa lebih belajar mandiri sehingga akan berhubungan positif terhadap prestasi akademik siswa. Beberapa studi yang ada sebelumnya menunjukkan bahwa pemberian pekerjaan rumah berpangaruh positif terhadap hasil belajar/ prestasi belajar terhadap siswa (Safitri, 2014; Puspitasari 2014).

Sebagian besar guru di Indonesia termasuk guru Sekolah Dasar memiliki anggapan bahwa siswa yang aktif mengerjakan pekerjaan rumah maka pengetahuan yang semakin matang. Tidak jarang, jika guru- guru sekolah dasar memberikan pekerjaan rumah dengan intensitas terus- menerus dan jumlah yang banyak. Dengan demikian adanya pekerjaan rumah tersebut siswa dapat memanfaatkan waktu di rumah dengan belajar dan berlatih melalui tugas-tugas yang diberikan oleh guru. Bagi siswa SD pemberian pekerjaan rumah dengan intensitas yang sering dan jumlah yang banyak hanya membuat siswa tertekan dan bosan terhadap tugas pekerjaan rumah yang yang harus siswa kerjakan. Studi yang dipublikasi Journal of Experimental Education menyebutkan 56\% siswa di California menganggap PR merupakan sumber utama stress (washingtonpost, 2014). Duke University telah meninjau lebih dari 60 penelitian tentang PR dari 1987 hingga 2003, menyimpulkan bahwa PR dari para guru yang bersifat akademis tak memiliki dampak positif pada prestasi belajar seorang siswa. Cooper (1989) dalam studinya mengemukakan bahwa secara substansial dampak positif PR terkait capaian siswa didapatkan oleh siswa dengan jenjang pendidikan lebih tinggi, sementara bagi siswa pada jenjang pendidikan dasar dampak positif terkait frekuensi pemberian PR tidak begitu berarti. Dengan demikian tidak selalu intensitas pemberian pekerjaan rumah berpengaruh positif terhadap hasil atau prestasi belajar siswa SD.

Berdasarkan studi yang ada terkait pekerjaan rumah bagi siswa SD, ada beberapa bentuk pekerjaan rumah yang diberikan oleh guru kepada siswa. Bentukbentuk pekerjaan rumah untuk siswa SD tersebut yaitu soal-soal latihan yang diambil dari Worksheet/LKS, soal- soal latihan yang diambil dari buku paket, soal yang dibuat oleh guru, menghafal perkalian, kerajinan tangan (menggambar, membuat hiasan kelas, menganyam dan membuat poster), karya tulis seperti menulis pengalaman selama liburan sekolah dan membuat surat (Sumekar, 2015). Berdasarkan pengamatan yang dilakukan ke beberapa sekolah dasar. Sebagian besar guru memberikan pekerjaan rumah dengan mengambil soal yang ada di Worksheet/LKS. Jumlah soal yang diberikan pun sangat banyak. Rata- rata minimal 4 halaman dengan jumalh soal kurang lebih 70 soal dalam satu kali tugas pekerjaan rumah. Tidak jarang hal tersebut menimbulkan perdebatan dimasyarakat.

Pemberian pekerjaan rumah bagi siswa SD di Indonesia menimbulkan pro dan kontra. Bagi pihak yang kontra, PR yang bersifat akademis dianggap tak memberi banyak manfaat bagi siswa atau pelajar sekolah. PR dianggap menjadi penyebab stress sehingga menyebabkan PR hanya dikerjakan asal-asalan. Hal ini terjadi saat 
anak merasa tidak mengerti mengenai tugas yang diberikan atau tugas dirasakan membingungkan, sulit, atau terlalu banyak. Penyebab lainnya ialah lepasnya pengawasan oleh orangtua terhadap kegiatan sekolah anaknya, dimana mereka hanya mendapat sedikit bantuan, atau adanya orangtua yang kurang memiliki pengetahuan tentang bagaimana membantu mengerjakan PR anak. Kasus lainnya, orang tua tidak hanya menawarkan bantuan, tetapi juga melakukan PR itu sendiri bila terdapat kesulitan, untuk menghemat waktu, atau merasa kasian pada anak (Corno \& Xu, 2004). Selain itu, ditemukan bahwa siswa-siswa di kelas awal yang mengalami kesulitan di sekolah membutuhkan waktu yang lebih lama dalam mengerjakan PR, yang diduga menyebabkan, meningkatkan kecemasan, kebosanan, kelelahan fisik dan emosional, serta demotivasi (Cooper et al., 2006; Trautwein et al., 2009).Orangtua memandang guru kurang kreatif dan variatif dalam memberikan soal karena hanya mengambil dari LKS. Bentuk tugas pekerjaan rumah yang berjalan di Indonesia tersebut dinilai kurang sesuai sehingga menuai protes dan berharap ingin segera ditiadakan karena dianggap membebani siswa SD dan orangtua.

Pada tingkat dasar (SD), pemberian PR seharusnya dilakukan dengan tujuan utama untuk meningkatkan regulasi diri dan motivasi siswa. Ditekankan bahwa pemberian PR untuk siswa SD dimaksudkan sebagai pengembangan kemampuan inisiatif dalam pembelajaran, juga dalam proses regulasi diri seperti, perencanaan, mengelola waktu, serta mempertahankan atau memeroleh kembali motivasi saat mengalami kemunduran. Namun, banyak siswa yang mungkin tidak menyadari tujuan tersebut, sehingga dalam dalam banyak kasus PR justru mengurangi dibandingkan meningkatkan motivasi siswa (Cooper, 1989; Cooper et al., 2006; Trautwein et al., 2009; Ramdass \& Zimmerman, 2011).

Guru sekolah dasar harus memahami tingkat kesulitan atau beban pekerjaan rumah yang sesuai dengan tingkat usia siswa SD. Guru SD dapat mencoba untuk menggabungkan PR yang diberikan dengan elemen bermain. Terdapat nilai lebih yang didapat bila guru merancang PR yang melibatkan aktivitas yang diminati siswa. Disamping itu, guru diharapkan untuk membantu siswa melakukan coping atau prosedur lainnya untuk mengelola stres saat mengerjakan PR yang dirasakan sulit. Upaya yang terkoordinasi antara orang tua, guru, maupun pihak lainnya sangat diperlukan dalam memberikan kondisi maksimal dalam mendukung aktivitas dan prestasi siswa dalam hal PR (Corno \& Xu, 2004). Selain itu, guru harus memahami penggunaan LKS dan tujuan dari diberikannya PR kepada siswa, apakah pemberiannya tepat secara kualitas dan kuantitas, serta bagaimana strukturnya agar layak diajarkan di kelas. Penting untuk mengukur efeknya terhadap kemampuan siswa, waktu pengerjaan, penyelesaian, kebiasaan, dan bantuan atau dukungan dari keluarga. Pada tingkat dasar, keterlibatan orang tua dinilai sebagai variabel penting dalam aktivitas yang berhubungan dengan PR, khususnya bagi siswa-siswi yang memiliki pencapaian rendah (Epstein, 1983). Idealnya, frekuensi pemberian PR untuk siswa SD sebagai berikut (Cooper, 1989):

- Kelas 1-3 = 1-3 PR per minggu, dengan waktu pengerjaan tidak lebih dari 15 menit

- Kelas 4-6 = 2-4 PR per minggu, dengan waktu pengerjaan 15-45 menit.

Maka dari penelitian ini bertujuan untuk mendeskripsikan bagaimana penerapan pemberian tugas melalaui pekerjaan rumah (PR) di SD>

\section{METODE}

Desain penelitian ini adalah Literature Review atau tinjauan pustaka. Studi literature review adalah cara yang dipakai untuk megumpulkan data atau sumber yang berhubungan pada sebuah topik tertentu yang bisa didapat dari berbagai sumber 
seperti jurnal, buku, internet, dan pustaka lain. Literature Review ini di sintesis menggunakan metode naratif dengan mengelompokkan data-data hasil ekstraksi yang sejenis sesuai dengan hasil yang diukur untuk menjawab tujuan

\section{HASIL DAN PEMBAHASAN}

Pengertian Pekerjaan Rumah

Pekerjaan rumah merupakan tugas yang diberikan oleh guru yang dimaksudkan untuk dikerjakan di luar jam sekolah (Cooper, 2001: 3), pekerjaan rumah juga dikatakan menjadi suatu strategi pembelajaran yang disebabkan karena lebih banyak faktor yg mempengaruhi di dalam proses pembelajaran. Oleh karena itu pekerjaan rumah masih menjadi salah satu pilihan strategi belajar yang banyak dipergunakan di dunia akademis. Hal ini karena pekerjaan rumah dapat memperpanjang waktu yang diperlukan dalam kegiatan akademis. Pemberian pekerjaan rumah memberikan kesempatan kepada siswa untuk mempraktekkan dan belajar materi pelajaran tanpa batasan waktu dan tempat.

Tujuan Pemberian Pekerjaan Rumah

Tujuan pemberian pekerjaan rumah secara garis besar dapat dikategorikan menjadi tiga (Van Voorhis: 2004):

a. Intruksional

Tujuan-tujuan dari pemberian pekerjaan rumah kepada siswa yang bersifat instruksional merupakan tujuan yang paling familiar bagi guru. Tujuan-tujuan tersebut antara lain sebagai latihan, persiapan untuk pertemuan berikutnya, peningkatan partisipasi dalam belajar, pengembangan pribadi (soft skills), dan sebagainya.

b. Komunikatif

Meskipun kurang begitu disadari oleh para guru dalam memberikan pekerjaan rumah kepada para siswa tujuan yang bersifat komunikatif sangat penting sebenarnya. Hal ini karena pada dasarnya pekerjaan rumah dapat memacu komunikasi antara para siswa, keluarga dan guru. Hal ini dapat terlihat dalam bentuk tugas yang dirancang untuk mendorong komunikasi guru dan orang tua, hubungan anak dengan orang tua, anak dengan orang dewasa lainnya, dan bahkan anak dengan teman sekelompoknya.

c. Politis

Pekerjaan rumah dapat berfungsi secara politis jika hal itu dilakukan untuk memenuhi suatu kebijakan atau kepuasan masyarakat (Van Voorhis: 2004). Pekerjaan rumah memberikan sinyal kepada orang tua dan masyarakat bahwa sekolah memiliki standar akademik yang ketat dan harapan-harapan tentang kinerja siswa. Hal ini ditunjukkan dengan beberapa sekolah secara jelas menyatakan bahwa sekolah memiliki kebijakan terkait dengan pemberian pekerjaan rumah misalnya frekuensi, lama pengerjaan, prosedur, peran orang tua dalam proses penyelesaian pekerjaan rumah.

Keuntungan memberikan pekerjaan rumah

a. Memperdalam keterampilan dan pngetahuan baru

b. penguatan melalui latihan, penerapan, transfer, dan pengayaan dari apa yang telah dipelajari di kelas sehingga memungkinkan untuk terjadinya pengintegrasian berbaagai ketrampilan yang terdapat di dalam kurikulum.

c. Siswa yang mendapat tugas pekerjaan rumah berarti dirinya harus membaca lebih awal sebelum dirinya mengikuti pelajaran di kelas. Dari itu, pekerjaan rumah mempersiapkan siswa untuk berpartisipasi di kelas secara bermakna, sehingga memungkinkan siswa untuk dapat berpartisipasi secara aktif. Keaktivan 
didorong oleh kesempatan dan kesiapsiagaan psikologis yang lebih awal ketika mengikuti pelajaran di kelas.

d. Dapat menjadikan siswa semakin memiliki kemandirian

Pekerjaan Rumah yang Bermakna

Hasil penelitian memberikan beberapa catatan untuk pelaksanaan pemberian pekerjaan rumah yang baik dari guru (Wolfe, 2003) antara lain:

a. Pekerjaan rumah akan efektif jika dirancang dengan baik, artinya tugas tersebut memang dirancang dalam proses pembelajarannya sehingga memungkinkan siswa untuk menyadari akan tugasnya terait dengan materi tersebut.

b. Pekerjaan rumah memang telah direncanakan/dipersiapkan untuk dikerjakan di luar jam pelajaran sebagai bentuk latihan lebih luas atau memperdalam suatu materi.

c. Melalui persiapan yang matang guru mampu menjelaskan, memberikan contoh, mengantisipasi potensi-potensi kesulitan sehingga pekerjaan rumah bukanlah dipersepsi sebagai beban namun sebagai tantangan dan tuigas yang harus diselesaikan.

d. Pekerjaan rumah diberikan dalam bentuk yang sesederhana mungkin untuk siswa belajar, merasa kompeten, dan sebagainya

e. Tidak merancang pekerjaan rumah sebagai hukuman. Para pendidik pada umumnya sepakat tidak boleh ada kekerasan di dalam pendidikan baik dalam bentuk yang halus dan tertutup ataupun sampai dengan dalam bentuk yang kasar dan bersifat terbuka (overt)

Guru konsekuen dan bertanggung jawab atas pekerjaan rumah yang diberikan, maksudnya adalah tidak sekedar memberikan tugas namun juga memonitor dan mengevaluasi hasil, serta melaporkan hasil kepada siswa

Pentingnya Pemberian Tugas Pekerjaan Ruman (PR)

Seluruh guru (partisipan) mmemahami tentang definisi PR. Salah satu definisi PR yang diungkapkan salah satu partisipan, "Tugas mandiri yang harus dikerjakan siswa sebagai tugas belajar di rumah untuk mengingatkan kembali materi yang sudah dipelajari di sekolah". Keberadaan PR itu penting juga disampaiakan $100 \%$ pastisipan. Para partisipan mengatakan beberapa tujuan adanya PR yaitu

a. Untuk mengingatkan kembali

b. Sebagai motivasi

c. Melatih kedisiplinan.

d. Untuk menambah jam belajar siswa di rumah karena waktu di rumah lebih banyak

e. Menumbuhkan rasa tanggung jawab dalam belajar

f. Supaya lebih memahai materi

\section{Penerapan Metode Pemberian Tugas Pekerjaan Rumah (PR)}

Penerapan metode pemberian tugas pekerjaan rumah (PR) pada pada siswa di 5 SD digambarkan berdasarkan hasil wawancara dengan guru kelas, maupun berdasarkan observasi langsung di lapangan. Diantara hasil wawancara tersebut adalah sebagai berikut, "metode pemberian tugas pekerjaan rumah (PR) terdiri dari dua bentuk yakni tugas pekerjaan rumah dalam bentuk individu yakni yang harus dikerjakan setiap siswa secara perorangan dan pekerjaan rumah yang diberikan berdasar kelompok belajar, selama ini pemberian tugas pekerjaan rumah (PR) dalam bentuk individu memang sudah berjalan dengan baik akan tetapi masih ada beberapa siswa yang sering tidak membuat tugas pekerjaan rumah (PR) sedang kan untuk tugas pekerjaan rumah (PR) dalam tugas kelompok, juga sudah berjalan dengan baik akan tetapi tidak semua kelompok siswa berperan aktif dalam mengerjakan tugas PR 
kelompok tersebut, masih ada beberapa siswa yang hanya mengandalkan hasil kerja teman sekelompoknya dan beberapa siswa"

Hasil wawancara dan observasi juga didapatkan bentuk tugas yang diberikan kepada siswa sebagai PR berbentuk soal esay, pilihan ganda, dan laporan. Data $50 \%$ partisipan mengatakan bahwa soal yang digunakan untuk PR diambil dari LKS, $50 \%$ mengatakan soal diambil dari buku, LKS dan buat sendiri. Jumlah soal yang diberikan 1-10 soal, jika dari LKS romawi I, II, dan III. Strategi guru (partisipan) dalam memberikan PR sebagai berikut:

a. Memberikan soal, mengerjakan LKS/bahan pendukung siswa, dan tugas kelompok belajar

b. Selalu memberikan PR walaupun tidak terlalu banyak tapi secara terus menerus

c. siswa menuliskan tugasnya di buku catatan siswa, kemudian memberitahukan kepada siswa bahwa nilai PR akan dimasukkan dalam penilaian tugas di rumah, bagi siswa yang disiplin mengerjakan PR akan mendapatkan bintang kedispilinan

d. Memberikan PR tidak terlalu banyak, rata yang bisa memperdlam materi dengan berlatih

Kendala-Kendala Dalam Penerapan Metode Pemberian Tugas Pekerjaan Rumah (PR) Terdapat beberapa kendala yang di hadapi dalam menerapan metode pemberian tugas pekerjaan rumah (PR) berdasarkan wawancara dan pengamatan.

a. Semua guru (pertisipan) mengeluhkan adanya siswa sering tidak mengerjakan PR dengan berbagai alasan. Hal tersebut menandakan kurangnya kesadaran siswa dalam mengerjakan tugas PR

b. Semua guru (pertisipan) mengeluhkan mengatakan kurangnya perhatian orang tua terhadap tugas belajar siswa di rumah.

Upaya-Upaya Dalam Memaksimalkan Penerapan Metode Pemberian Tugas Pekerjaan Rumah (PR). Beberapa upaya partisipan dalam memaksimalkan penerapan metode pemberian tugas pekerjaan sebagai berikut

a. Memberikan soal bervariasi

b. Mengkomunikasikan dengan orangtua

c. Memberi hukuman berupa menambah jumlah PR dan disuruh mengulang kembali mengerjakan PR.

d. Selalu mengkoreksi PR

e. memberikan punishmen dengan mengerjakan PR di pojok baca dengan tambahan membaca buku menghubungi orangtuanya agar lebih memperhatikan anak dalam belajar di rumah

Harapan partisipan kepada siswa dalam penyelesaian PR

a. Siswa belajar dengan kesadaran sendiri, motivasi belajar meningkat dan belajar bekerja sama.

b. Siswa sering belajar dan sering diulang-ulang.

c. Siswa bisa membagi waktu untuk belajar sendiri

d. PR menjadi hal yang didambakan siswa, siswa senang mengerjakan PR dan bahkan meminta guru memberikan PR

\section{SIMPULAN}

Pekerjaan rumah sebenarnya sudah lama terselenggara dalam sistem pendidikan. Bahkan sebagian besar para pendidik sampai sekarang masih memanfaatkannya untuk memberikan tugas kepada para siswanya. Namun demikian, tidak semua pemberian tugas pekerjaan rumah dilakukan dengan semestinya, sehingga berakibat pada persepsi yang salah tentang pekerjaan rumah itu sendiri. Di pihak lain, masih banyak para pendidik sangat mengandalkan cara pemberian tugas 
melalui pekerjaan rumah. Hal itu dilakukan dengan beragam argumentasi mulai dari untuk mengatasi terbatasnya jam tatap muka di sekolah, memperluas pemahaman siswa, sampai dengan melatih siswa untuk mampu memecahkan masalah sendiri. Dalam kerangka membangun jembatan kemitraan dengan orang tua tidak ada salahnya metode yang sudah sangat klasik ini diandalkan untuk dipergunakan membangun kerja sama. Kerja sama yang terbangun lama kelamaan akan mampu menjadi tulang punggung terselenggarakannya berbagai program pendidikan.

\section{DAFTAR PUSTAKA}

Cooper, H. (1989). Homework.White Plains, NY: Longman

Cooper, H., Jackson, K., Nye B., \&Lindsay, J.J (2010). A Model of K omework's Influence on the Performance Evaluations of Elementary School Students. Pages 181-199.

Cooper, H., \& Valentine, J.C. (2001). Using research to answer practical questions about

homework. Educational Psychologist, 36, 143-153.

Corno, L \& Xu, J. (2004). Homework as the Job of Childhood. Theory into Practice. $43(3), 227-233$

Epstein, J. L. (1983). HOMEWORK PRACTICES, ACHIEVEMENTS, AND BEHAVIORS OF ELEMENTARY SCHOOL STUDENTS. Working paper. Johns Hopkins Univ., Baltimore, Washington, DC.

Kohn, A. (2006, September). Abusing research: The study of homework and other examples. Phi Delta Kappan, 8-22.

Margolis, H. (2010). Resolving Struggling Learners' Homework Difficulties: Working With Elementary School Learners and Parents. Pages 5-12

McKenney, S., \& Reeves, T.C. (2014). Educational Design Research. Handbook of Research on Educational Communications and Technology. New York: Springer Science+Business Media New York

Peachock, GG. 2010. Practical handbook of school psychology: effective practices for the 21st century. Guilford Press: New York.

Plomp (2007). "Educational Design Research: An Introduction", dalam An Introduction to Educational Research. Enschede, Netherland: National Institute for Curriculum Development

Puspitasari, L.(2014). Kontribusi Nilai Pekerjaaan Rumah terhadap Prestasi Belajar IImu Pengetahuan Social Kelas VA SD Negeri Giwangan Yogyakarta. Yogyakarta: PGSD FKIP UNY

Ramdass, D \& Zimmerman, B. J. (2011). Developing Self-Regulation Skills: The Important Role of Homework. 22(2), 194-218

Puspitasari, L.(2014). Kontribusi Nilai Pekerjaaan Rumah terhadap Prestasi Belajar Ilmu Pengetahuan Social Kelas VA SD Negeri Giwangan Yogyakarta. Yogyakarta: PGSD FKIP UNY.

Strauss, V. (2014). https://www.washingtonpost.com/news/answersheet/wp/2014/03/13/homework-hurts-high-achieving-students-studysays/?utm_term=.66c6b945f2bd

Sumekar, Septyara Hanajayanti. (2015). Penerapan Pemberian Pekerjaan Rumah dalam Meningkatkan Motivasi Belajar Siswa SD Negeri 2 Kadipaten, Kecamatan Andong, Kabupaten Boyolali, Tahun Pelajaran 2014/2015. Surakarta: PGSD FKIP UMS

Trautwein, U., Niggli, A., Schnyder, I., Lüdtke, O. (2009). Between-Teacher Differences in Homework Assignments and the Development of Students' Homework 
SHEs: Conference Series 4 (1) (2021) $144-151$

Effort, Homework Emotions, and Achievement. Journal of Educational Psychology, 101(1), 176-189.1

Van Voorhis, F.L. 2004. Reflecting on the Homework Ritual: Assignments and Designs. Theory into Practice. 43, 205-212.

Vatterott, C. 2009. Rethinking homework : best practices that support diverse needs. ASCD: Alexandria, USA. 